\title{
SILÊNCIOS E VAZIOS EM JERUSALÉM: RELAÇÕES INTERTEXTUAIS
}

\author{
Ibrabim Alisson Yamakawa* \\ Luzia Aparecida Berloffa Tofalini**
}

RESUMO: Jerusalém de Gonçalo M. Tavares, objeto base das análises empreendidas neste artigo, estabelece interlocuções com diversos discursos produzidos em diferentes épocas. Entre eles se podem contar os discursos filosóficos, sociológicos e religiosos. As relações intertextuais ocorrem tanto no domínio verbal quanto nos domínios do silêncio. Elas se apresentam de forma explícita, por vezes, e de modo mais velado, por outras. O objetivo fulcral deste trabalho consiste na articulação das interfaces entre literatura, trauma, silêncio e vazio à luz dos estudos sobre intertextualidade, especialmente de Júlia Kristeva. Valendo-se dos expedientes do silêncio e do vazio, afloram as memórias de dor, sofrimento e morte. Os vazios rondam as personagens de Jerusalém e encontram-se repletos de silêncios. Tais silêncios potencializados revelam a existência de diferentes discursos. Convocam-se estudos relacionados ao silêncio, desenvolvidos por Eni P. Orlandi, para dar suporte às discussões. Quanto à problemática do vazio, recorre-se principalmente aos apontamentos de Gilles Lipovetsky.

PALAVRAS-CHAVE: Gonçalo M. Tavares; Intertextualidade; Jerusalém; Silêncio; Vazio.

\section{Considerações iniciais}

É de palavras encharcadas de silêncio que a literatura é feita. Palavras inundadas de silêncio são em essência "palavras' rica de 'vozes"' (SCIACCA, 1967, p. 52) e repletas de intertextos. Por isso, não é de modo algum por acaso que Jerusalém, de Gonçalo M. Tavares, é eleito como objeto de análise das relações intertextuais de silêncios decorrentes do vazio.

\footnotetext{
* Doutorando no Programa de Pós-graduação em Letras da Universidade Estadual de Maringá.

** Professora do Programa de Pós-Graduação em Letras, da Universidade Estadual de Maringá (Uem). Doutora em Letras pela Universidade Estadual Paulista Júlio de Mesquita Filho (Unesp)
} 
Jerusalém - o terceiro romance da série $O$ Reino ${ }^{1}$ - é, sem dúvida, um romance que se entrega ao silêncio e faz dele uma de suas mais importantes estratégias. Trata-se de um texto repleto de vazios ${ }^{2}$ e silêncios e, consequentemente, é atravessado por múltiplos discursos e intertextos.

Jerusalém pode ser considerado um romance do trauma: repleto de analepses e prolepses, fragmentações de imagens, desordem de acontecimentos, estilhaçamento da ação. É o romance mais fragmentado da tetralogia e se dispersa em três personagens centrais: Mylia, Ernst e Theodor. Mylia é uma mulher esquizofrênica que foi internada pelo próprio marido (Theodor Busbeck) em um hospital para doentes mentais. No hospital, Mylia conhece outro paciente, também esquizofrênico, chamado Ernst Spengler, com quem tem um filho.

Essas personagens convivem com o trauma, uma vez que são vítimas da violência, da indiferença e da barbárie. Qualquer que seja a sua relação com o trauma, as personagens não conseguem externar seus sentimentos com palavras. Acossadas por profundos vazios, elas silenciam. Tais silêncios gerados pelos traumas e pelas dores encontram-se plenos de sentido. Eis o motivo pelo qual o silêncio assume categoria de protagonista na história. Há silêncios em todas as instâncias da narrativa: "O silêncio excessivo não vinha da rua, mas sim da própria casa, do interior da casa" (TAVARES, 2006, p. 83). Essas palavras sugerem, metaforicamente, que o silêncio nasce na interioridade. Tal como na casa de que fala o romance, o silêncio impõe-se e penetra o "eu" das personagens e o interior do próprio romance.

\footnotetext{
${ }^{1}$ Trata-se de uma série composta por quatro romances: Jerusalém; Aprender a rezar na era da técnica;

2 O silêncio é uma instância plena de sentido. David Le Breton (1999) propõe que o silêncio é o que permite à linguagem ser discernível segmentável e inteligível. Sem um espaço que se interpusesse entre os signos, os sentidos jamais se construiriam. O vazio, por sua vez, diferencia-se do silêncio, mas ele não é de maneira alguma desprovido de sentido, embora, ele, muitas vezes seja erroneamente associado a essa ideia. Entretanto, o exame pormenorizado dos fatos da linguagem irá demonstrar que o vazio apresenta-se com outra instância também plena de sentido que só se manifesta entre silêncios (MAY, 1986). A realização do vazio exige o silêncio para significar.
} 
Todas as palavras de Jerusalém são revestidas de silêncio, mas quando ele se sobrepõe à palavra aniquilando-a, é porque ela é incapaz de conter em si tudo aquilo que o silêncio tem capacidade de expressar. As palavras são frágeis perante a potência do silêncio e se desfazem diante do inefável, porque o silêncio, muito provavelmente, se configura no único caminho de expressão da angústia, do inefável e do indizível. Por exemplo, quando se tem algo a dizer que não cabe em palavras (trauma ou dor) perfila-se o silêncio: "Sentada numa cadeira desconfortável pensava nas palavras fundamentais da sua vida. Dor, pensou, dor era uma palavra fundamental” (TAVARES, 2006, p. 7). Mylia “[...] já não conseguia colocar as palavras numa balança [...]” (TAVARES, 2006, p. 67). Os silêncios da obra atestam que não há um limite do que pode ser "dito” e, ao mesmo tempo, é um anúncio de uma realidade impensável que jamais poderia ser traduzida em sua completude.

O silêncio em Jerusalém apresenta-se como veículo de expressão da experiência traumática e, ao mesmo, como condição fundamental para a realização da intertextualidade. $\mathrm{O}$ trauma "permanece inacessível à transcodificação em linguagem [verbal] e reflexão" (ASSMANN, 2011, p. 227). O que faz com que o trauma se manifeste, depois, de maneira intersticial, lacunar, difusa e repleta de vazios em sua estrutura que mina a ordem da palavra e a previsibilidade dos sentidos e que, consequentemente, segmenta a experiência traumática facultando a realização de intertextos.

Essa renúncia à palavra é essencial porque a origem dos sentidos está no silêncio, como bem lembra Eni Orlandi, ele é "princípio de toda significação" (ORLANDI, 2007, p. 68), porém, inapreensível. O sentido do silêncio, portanto, consiste em reconhecer os processos de significação que ele põe em jogo (ORLANDI, 2007). O silêncio entra, justamente, nesse movimento que existe no discurso entre o "um" e o "múltiplo", entre língua e ideologia e entre reduplicação e deslocamento. De modo que o silêncio caracteriza um movimento contraditório "tanto do sujeito quanto do sentido, fazendo o entremeio entre ilusão de um sentido só [...] e o equívoco de todos os sentidos” (ORLANDI, 2007, p. 17). Esse movimento que ocorre no silêncio é o que possibilita os sentidos, inclusive o entrecruzamento de vozes intertextuais. 
Tanto o sujeito quanto o sentido estão dispersos no silêncio. Os sujeitos e os sentidos movem-se pelo silêncio, mesmo que a identidade do sujeito se conforme com uma ilusão de unidade e linearidade, mas sua identidade é atravessada por múltiplos discursos fazendo o sujeito tão errático quanto os sentidos. Os sujeitos, portanto, não estão fechados dentro de uma formação discursiva específica. Eles, ao contrário, se movem entre diferentes regiões, produzindo sentidos múltiplos. Essa caracterização é importante, porque, dessa forma, ao conceber o silêncio como uma instância propícia para a produção de sentidos na sua relação com o sujeito, a leitura do silêncio em um texto literário extrapola a ordem da palavra como também extrapola a própria obra. Consequentemente, no silêncio se constroem pontes intertextuais.

Para entender em que consiste essa relação intertextual que ocorre na confluência do trauma, do vazio e do silêncio, é necessário articular as interfaces entre silêncio, vazio e trauma à luz dos estudos sobre a intertextualidade. Busca-se compreender a maneira pela qual o silêncio e o vazio ao representarem o trauma possibilitam a aproximação de Jerusalém com outras obras do cenário literário e extraliterário. Este artigo pretende contribuir para reconhecimento do vazio e do silêncio como instâncias produtoras de sentido em Jerusalém, pois tanto o silêncio quanto o vazio ajudam a significar os traumas representados por meio de intertextos. Para tal tarefa destacam-se as obras de Júlia Kristeva (2005) e Tiphaine Samoyauilt (2008) que ajudam na compreensão dos limites do conceito de intertextualidade. Já o estudo de Eni P. Orlandi (2007) auxilia as leituras em relação ao silêncio e o de Gilles Lipovetsky (2005) complementa as leituras em torno do vazio.

\section{1. (Re)visitando a teoria: intertextualidade}

O trajeto iniciado desde Mikhail Bakhtin até o conceito de intertextualidade cunhado por Júlia Kristeva, depois seguido pelas considerações de Roland Barthes e, em então, passando pelos escritos de Gérard Genette, entre outros autores dedicados ao estudo da intertextualidade, ressalta-se, em primeiro lugar, a importância do conceito de intertextualidade para os estudos literários; em segundo, a imprecisão desse conceito, haja vista que ele foi retomado por outros autores com diferentes entendimentos sobre ele. Por isso, faz- 
se necessário fazer uma breve revisão sobre esse conceito, com o intuito de esclarecer o que se toma por intertextualidade.

Aliás, o conceito foi tão usado no campo dos estudos literários que em seu próprio desdobramento ocasionou “a bipartição de seu sentido em duas direções distintas: uma torna-a um instrumento estilístico, linguístico mesmo, designando o mosaico de sentidos e de discursos anteriores, produzido por todos os enunciados (seu substrato) [...]" (SAMOYAUILT, 2008, p. 13). O que significa que a intertextualidade é resultado de um trabalho técnico, sofisticado, uma injunção à interpretação, por vezes, inconsciente, segundo o qual o autor e o leitor recorrem à memória discursiva para retomar, reproduzir e ressignificar sentidos presentes de textos precedentes. Enquanto que “[...] a outra torna-se uma noção poética, e a análise aí está mais estritamente limitada à retomada de enunciados literários (por meio da citação, da alusão, do desvio, etc.)" (SAMOYAUILT, 2008, p. 13). Nesse caso, todas essas práticas, com exceção da alusão, se inscrevem no texto, em maior ou menor grau, com nitidez. O que significa que essas práticas pertencem ao campo da palavra propriamente dita, porém, não excluem o silêncio de todo.

A leitura de um texto literário implica necessariamente o reconhecimento de que o texto literário é tanto composto por palavras quanto por silêncios e de que esse mesmo texto nunca está sozinho no tempo e no espaço, e de que ele não é apenas produto da inspiração pessoal. Não pode ser considerado, portanto, único e absolutamente ímpar, pois, um texto literário, em última análise, possui relações com outras obras no passado. O problema teórico relacionado à intertextualidade, aliás, é determinar como se dá esse relacionamento ou cruzamento de um texto sobre o outro.

Se se levar em conta o termo intertextualidade: -inter é um prefixo latino usado para expressar uma relação de reciprocidade, de mutualidade e de posição intermediária; enquanto que textualidade, por sua vez, deriva da palavra latina textum e guarda o sentido de entrelaçamento, de tessitura, de tecido ou teia discursiva, o que remete a ideia de que o processo de escrita envolve, necessariamente, o entrecruzamento de múltiplos textos. 
Julia Kristeva, a propósito, foi a primeira pesquisadora a usar o termo intertextualidade. Em Introdução à Semanálise, ela escreve que: "todo texto é absorção e transformação de um outro texto. Em lugar da noção de intersubjetividade, instala-se a intertextualidade [...]” (KRISTEVA, 2005, p. 68). Intertextualidade, nesse sentido, é como se lê e se localiza na história um determinado texto, retirando o privilégio do autor sobre o texto enquanto detentor dos sentidos. De forma que, para Julia Kristeva, texto e intertextualidade fazem parte de um processo dinâmico de construção de sentidos que são, essencialmente, marcados por outros dizeres. O sentidos, portanto, não são conteúdos, mas efeitos que podem ser percebidos em diferentes textos.

Influenciada pelo conceito de dialogismo bakhtiniano, segundo o qual todo discurso se constrói a partir de sua relação com outros discursos, sendo "condição essencial do próprio ser (existência) e do agir dos sujeitos (ações) que produzem a linguagem" (FLORY, 2015, p. 112), e sendo ao mesmo tempo a condição de possibilidade de existência dos sentidos, Julia Kristeva remodelou o conceito de dialogismo, propondo um novo conceito: a intertextualidade. Segundo a autora, os sentidos não são fixos, mas flutuantes e dependem da relação com outros elementos. Intertextualidade é, conforme essa autora, uma concepção "segundo a qual a palavra literária não é um ponto (um sentido fixo), mas um cruzamento de superfícies textuais, um diálogo de diversas escrituras; do escritor, do destinatário (ou da personagem), do contexto cultural atual ou anterior” (KRISTEVA, 2005, p. 66). Intertextualidade é um diálogo em constante movência. Trata-se de uma rede de conexões complexas, "muitas vezes inconscientes; logo, o intertexto, ou seja, aquilo que se possa perceber da relação de dois textos, pode não ser um objeto facilmente recuperável ou perceptível, mas estar diluído por todo o texto ou, ainda, a partir dele" (ARAÚJO; LOBO-SOUZA, 2009, p. 568), ou, até mesmo, estar disperso no silêncio.

Isso explica por que no ato de leitura de um texto literário se tem a falsa impressão de que aquilo que é lido é único, primeiro, original, assim como os sentidos depreendidos dele. $\mathrm{Na}$ verdade, muitas vezes, essas conexões não se apresentam de forma clara e consciente, mas velada e inconsciente. De fato, a respeito da conexão de sentidos, Eni P. Orlandi 
explica: "temos a ilusão de ser a origem do que dizemos quando, na realidade, retomamos sentidos pré-existentes. Esse esquecimento reflete o sonho adâmico: o de estar na inicial absoluta da linguagem, ser o primeiro homem, dizendo as primeiras palavras [...]" (ORLADI, 2009, p. 35). A autora ainda complementa que "quando nascemos os discursos já estão em processo e nós é que entramos nesse processo. Eles não se originam em nós" (ORLANDI, 2009, p. 35). Como se os sentidos apontassem para a inevitabilidade do horizonte intertextual. De modo que, ao levar em consideração o funcionamento do silêncio na linguagem enquanto uma instância propícia para a produção de sentidos, é que se rompe com essa ilusão de linearidade e unidade e se reconhece que quaisquer textos são e estão em pleno diálogo com outros discursos.

Em Introdução à Semanálise, Julia Kristeva propõe que “toda sequência se constrói em relação a uma outra [...] de modo que toda sequência está duplamente orientada para o ato de "reminiscência" (evocação de outra escrita) e para o ato de "intimação" (a transformação dessa escritura)" (KRISTEVA, 2005, p. 105, grifo nosso). Tal colocação permite elaborar uma relação estreita entre intertextualidade e silêncio. Supõe-se que o silêncio é entendido aqui como um continum e trabalha nessa constante movência de sentidos, a intertextualidade se manifesta, por sua vez, na segmentação desse mesmo movimento contínuo a partir da memória discursiva. O processo de produção de sentidos consiste em recuperar (reminiscência) e atualizar ou ressignificar (intimação) os sentidos já existentes.

Em Jerusalém a memória cumpre um papel decisivo para a operação do fenômeno intertextual, pois, as memórias do trauma das personagens desse romance estão sempre incompletas, estilhaçadas e dispersas no movimento contínuo do silêncio, fazendo com que as personagens e o leitor evoquem outros discursos e outras escrituras com o intuito de recompô-las e estabilizá-las. Há, por exemplo, um esforço notável para estabilizar essas memórias quando as personagens e o narrador insistem em marcar os dias e as horas ou quando os pacientes do hospital para doentes mentais liam cartas para se lembrar de quem eram: "era este o sentido [...] não te esqueças" (TAVARES, 2006, p.160). Em outro momento, lê-se que: “os pensamentos e as imagens sucediam-se - uma entrava dentro das 
outras não permitindo que a anterior permanecesse do princípio ao fim intacta [...] não terminava um raciocínio [...]" (TAVARES, 2006, p. 214). Segmentam-se as memórias da dor e do trauma e no intertexto é possível recompor a imagem do trauma a partir dos múltiplos discursos que nele estão atravessados.

Roland Barthes em $O$ rumor da língua também defende a movência dos sentidos no texto, muito embora, assim como Julia Kristeva ele não menciona o papel do silêncio. Para o autor, o texto é plural, imprimindo a ideia de que, "o texto não é coexistência de sentidos, mas passagem, travessia [...]" (BARTHES, 2004, p. 70). De fato, tal concepção sobre a categoria texto é bastante significativa e complementar para os estudos sobre o silêncio, pois o postulado de Roland Barthes corrobora o entendimento aqui apresentado de que o silêncio não é linguagem, mas que ele atravessa a linguagem. Além de que os sentidos também não estão prontos no texto, coexistindo simultaneamente e simplesmente aguardando serem decifrados pelo leitor. Os sentidos, ao contrário, são efeitos produzidos dentro de uma determinada conjuntura.

Por essa razão, é no silêncio que se realiza o intertexto: “O intertextual em que é tomado todo texto, pois ele próprio é intertexto, não pode confundir-se com alguma origem do texto: buscar as 'fontes', as 'influências' de uma obra” (BARTHES, 2004, p. 71). Gonçalo M. Tavares em Atlas da imaginação e do corpo escreve:

O fragmento é, pela sua natureza, um ponto onde se inicia; um fragmento nunca termina, mas é raro um fragmento não começar algo. Poderemos dizer que o fragmento é uma máquina de produzir inícios, uma máquina da linguagem, das formas de utilizar a linguagem - pois tal é a sua natureza. (TAVARES, 2013, p. 41).

E, de fato, essas considerações sobre o caráter de um fragmento são bastante importantes para este estudo sobre intertextualidade, silêncio e vazio, pois ao considerá-lo como tal, o fragmento apresenta-se como um fio de linguagem entre outros tantos fios na teia da linguagem. Retomando novamente o que Gonçalo M. Tavares afirma sobre o fragmento: "fragmento é um mecanismo de parto; de início, de começo; clínica" (TAVARES, 2013, p. 41). Não se trata, portanto, de considerar um fragmento como a origem ou fonte 
primária dos sentidos, mas enquanto possibilidade de sentidos, considerando que todos os fragmentos, quaisquer que sejam, são acompanhados de silêncio e se organizam em torno do vazio. Gonçalo M. Tavares ainda se questiona sobre o fragmento: "Por onde se começa? Onde se acaba?" (TAVARES, 2013, p. 40). Traçar a origem (o começo) de um fragmento não parece tão importante quanto perceber que um fragmento é possibilidade de construção de começos, de produção de sentidos.

Com efeito, o fenômeno intertextual implica reconhecer o texto como "um espaço de dimensões múltiplas, onde se casam e se contestam escrituras variadas, das quais nenhuma é original: o texto é um tecido de citações [...]” (BARTHES, 2004, p. 62). A concepção de intertextualidade de Roland Barthes, portanto, permanece bastante próxima do que foi proposto por Julia Kristeva, porém, Roland Barthes retoma "no seu modo de ver, a intertextualidade, reduzindo já um pouco o seu campo de ação [...]” (SAMOYAUILT, 2008, p. 23), aproximando o conceito dos usos da leitura.

Gérard Genette, por sua vez, desloca completamente o conceito de intertextualidade do campo linguístico/discursivo para o campo da poética criando um novo conceito chamado transtextualidade. Esse deslocamento permite ao pesquisador traçar uma fronteira entre o conceito de intertextualidade influenciado pelo dialogismo bakhtiniano e o que Gérard Genette apresenta como sendo intertextualidade de fato. A proposta desse autor não se restringe ao tratamento da interação entre textos em uma dimensão histórica e social, mas perceber que a relação entre textos implica a transformação de um texto sobre o outro, um texto inscrevendo-se no outro.

A interação entre textos "remete ao manuscrito apagado e re-escrito que deixa aparecer, em filigrana, vestígios variáveis do texto anterior - permite em primeiro lugar esclarecer relações entre um texto presente e um texto ausente, entre o atual e o virtual" (SAMOYAUILT, 2008, p. 32). Com o intuito de evitar ambiguidades e imprecisões resultantes de um conceito muito amplo como aquele postulado por Julia Kristeva e Roland Barthes, Gérard Genette distingue dois tipos de relações distintas: intertextualidade e hipertextualidade. 
Hipertextualidade, para Genette, consiste em um texto A que deriva em um texto B, isto é, hipertexto é "todo texto derivado de um texto anterior por simples transformação [...]" (GENETTE, apud, SAMOYAUILT, 2008, p.31). Por outro lado, intertextualidade se apresenta como manifestação de fato de um texto A em um texto B, sob três formas distintas: de forma explícita (citação), de forma menos explícita (plágio), de uma forma ainda menos declarada (alusão). Como se pode perceber, para esse autor, a intertextualidade situa-se mais ao campo da palavra.

Certo é que mesmo que o conceito de intertextualidade pertença tanto ao campo da linguística e do discurso quanto de uma noção poética vinculada à palavra literária, o que de fato importa no âmbito dos estudos sobre intertextualidade é compreender os efeitos de sentido que os intertextos produzem em determinadas circunstâncias. Os estudos sobre intertextualidade não se caracterizam em buscar as origens, consultar as fontes de influência de um autor, mas estabelecer relações de sentido que complementem a obra em questão. Embora, o conceito de intertextualidade não seja ainda plenamente definido, "pode-se afirmar, porém, que o fenómeno da intertextualidade desempenha, quer na produção, quer na recepção literárias, uma função relevante, que não encontra paralelo em qualquer outra classe de textos" (AGUIAR E SILVA, 2007, p. 628). Quando confrontado com o silêncio, o fenômeno intertextual impõe-se de maneira determinante, pois ao reconhecer que os efeitos de sentido estão sempre em movimento, e não presos ao texto, significa estabelecer que os sentidos transitam em outros textos e evocam necessariamente outros discursos.

\section{Cruzamentos de texto em Jerusalém: silêncios entre vazios}

Quando as palavras se convertem em silêncio e se cruzam no silêncio possibilitando diálogos e intertextos? Em Jerusalém, a resposta que se apresenta de maneira mais consequente é, seguramente, o silêncio que transborda nas palavras de Myllia a Ernst: "Se eu me esquecer de ti, Jerusalém, que seque a minha mão direita" (TAVARES, 2006, p. 154). Seria bastante difícil considerar esse fragmento como obra do acaso. E de fato, não o é. A frase dita por Mylia é uma citação (um fragmento) e muito embora tenha aparecido sob a forma 
de palavra, pois palavra e silêncio não se deixam separar, sugere que há algo a ser dito que as palavras apenas rodeiam, mas não são capazes de alcançar. É como se o que a personagem diz fosse maior do que o que as suas palavras representam, maior, inclusive, que os efeitos que tal citação pode provocar no romance.

A cada palavra é imprescindível reconhecer o silêncio na mais discreta das formas, pois é na articulação dos silêncios com a linguagem que o silêncio acaba se distinguindo, graças à sua autonomia em relação à palavra. Com efeito, tem-se um fragmento composto mais de silêncios do que de palavras, pois caso contrário, bastaria dizer que as palavras de Mylia derivam de um fragmento bíblico, mais especificamente, do Salmo 136 que diz: "Seu eu me esquecer de ti, ó Jerusalém, que minha mão direita se paralise" (BÍBLIA, Salmos, $136,5)^{3}$. Se se tratasse apenas das palavras, seria possível estabelecer uma relação do significado bíblico desse fragmento com o tema abordado no romance.

Logo, se poderia dizer que o respectivo Salmo expressa um tom saudosista que combina com a ambientação criada pelo narrador nessa mesma passagem do romance. Ernst reencontra Mylia depois de bastante tempo separados. Lê-se, nesse mesmo capítulo que "ninguém se aborrece quando no último instante é salvo ou quando reencontra uma pessoa do seu passado" (TAVARES, 2006, p. 153-4). E Ernst é tanto essa pessoa importante de seu passado quanto Mylia é quem o salva do suicídio. Ambos tinham se conhecido no hospital para doentes mentais Georg Rosenberg. Diagnosticado com esquizofrenia, assim como Myllia, Ernst estava internado para o seu tratamento. Lá, eles eram supervisionados pelo médico-gestor Gomperz, responsável pelos mais variados abusos, no sentido de que o médico determinava arbitrariamente o que se devia pensar e o que se devia esquecer. Para, "estar curado não era apenas deixar de ter determinados comportamentos, era ainda esquecer o trajecto que de novo os poderia recuperar" (TAVARES, 2006, p. 93).

\footnotetext{
${ }^{3}$ Em outras traduções, o mesmo trecho é encontrado no Salmo 137, 5. O Salmo 136 (ou 137) retrata a destruição de Jerusalém pelos babilônios em 586 a. C. Jerusalém foi ocupada pelos babilônios e, depois, completamente arrasada pelo exército invasor. Os hebreus ficaram exilados nas terras de seus captores. Esse Salmo é considerado um Salmo imprecatório, ou seja, o salmista suplica veementemente a Deus que puna todos os captores.
} 
Pode-se fazer um paralelo com Salmo 136, nesse sentido, pois assim como Ernst e Mylia, os hebreus cativos na Babilônia são impelidos a esquecer de sua pátria e desprezar a sua origem. De maneira análoga, o doutor Gomperz quer que seus pacientes se esqueçam de tudo sobre si mesmos e abandonem, portanto, sua identidade como parte do processo de cura. Mylia, em contrapartida, insistia que "Se eu me esquecer de ti, Georg Rosenberg, que seque a minha mão direita" (TAVARES, 2006, p. 181). E com isso, ela demonstra uma determinação para preservar as memórias como um ato de resistência contra o doutor Gomperz, resistindo às pressões do hospital Georg Rosenberg.

Se se tratasse apenas das palavras, ainda se poderia propor que assim como os hebreus, as personagens Mylia e Ernst são forçados a se render e a se conformar. Destaca-se, pois, o seguinte: "Nossos opressores exigiam de nós um hino de alegria [...]” (BÍBLIA, Salmos, 136, 3). Ernst, por exemplo, em certa passagem diz: "Chamo-me Ernst. Ernst Spengler. Gosto de estar aqui" (TAVARES, 2006, p. 77), referindo-se à casa de doentes mentais Georg Rosenberg. Outras personagens que habitam o hospital, assim como Ernst, também se encontram em uma situação deplorável e se conformam quer porque uns estão completamente resignados como Martha que diz: "fui feliz três vezes [...] quando minha mãe me deixou brincar no jardim. Depois a minha mãe trouxe-me para aqui. Pensei que era um jogo" (TAVARES, 2006, p. 73), quer porque antes de estar internados no hospital viviam em situação pior, como Janika que confessa que gosta de fazer comida. "Passei fome, diz Janika" (TAVARES, 2006, p. 75). Por isso, contenta-se em poder fazer comida, ainda que coma mal.

Todavia, esse versículo colocado por Mylia é muito mais do que apenas palavras retiradas da Bíblia. As palavras de Mylia guardam em seu íntimo toda dor e todo vazio que ela não consegue lidar. Por isso, há no silêncio que nasce do vazio de suas palavras a presença de um trauma. Dessa forma, as palavras vazias convertem-se em silêncio plurissignificativo atestando também a presença de vazios que habitam nas personagens.

Em "Se eu me esquecer de ti, Jerusalém, que seque a minha mão direita" (TAVARES, 2006, p. 154) e "Se eu me esquecer de ti, Georg Rosenberg, que seque a minha mão 
direita" (TAVARES, 2006, p. 181), há silêncios que preenchem vazios e que propõem uma multiplicidade de começos, de inícios, possibilitando acelerar a relação entre linguagem e pensamento, discurso e intertexto. Os fragmentos - que se apresentam em torno desse vazio ou vácuo do incomunicável que é a experiência traumática - evocam necessariamente o silêncio. Deve-se, portanto, notar que os fragmentos ditos por Mylia se apresentam sob a forma de uma promessa, mas com o peso de uma advertência. Mantém-se o tom imprecatório do fragmento, mas muda-se o destinatário. Há, portanto, não ditos nessa passagem.

Destaca-se o seguinte: "se eu me esquecer de ti, Jerusalém". Jerusalém antes se apresenta como uma referência bíblica, afinal o fragmento mencionado por Mylia é um versículo extraído de um Salmo. Ao mesmo tempo, entretanto, essa primeira possibilidade de sentido de Jerusalém, como posição geográfica, enquanto cidade do Oriente Médio, Terra Prometida aos Hebreus por Deus, não descarta ou anula outra possibilidade: a ideia de Jerusalém enquanto ideia de guarida, de refúgio, de esperança, de promessa a ser cumprida, de lar, de pertencimento, de origem, de sagrado e de paz. É como se a personagem dissesse para si mesma: “em Jerusalém, eu sou”. Quer dizer, ela pertence à Jerusalém e em Jerusalém ela é o que é. "Se eu me esquecer de ti”" sugere a possibilidade de esquecimento de si mesma. Não se trata, somente, de reconhecer Jerusalém como cidade ou de se referir a Deus, mas de uma representação simbólica da referência máxima de esperança para encontrar o seu lugar de pertencimento e superar a sensação de vazio e de abandono.

Ao mesmo tempo, Jerusalém possibilita o deslizamento de sentidos que traz a ideia de guerra, de discórdia, de massacre, de incerteza, de contestação e de desavença. Além disso, se se associar a ideia de Jerusalém com a referência às pilhas de cadáveres e aos campos de concentração que aparecem nos livros lidos por Theodor Busbeck, bem como os nomes germanizados de algumas personagens que evocam a memória de Shoab $b^{4}$. Jerusalém (que aparece escrito apenas uma vez em todo romance, além do título) ganhará status

${ }^{4}$ Em História, memória e literatura: o testemunho na era das catástrofes (2012), Márcio Seligmann-Silva propõe o termo Shoah ao invés de Holocaustos. Segundo esse autor, Shoah significa "catástrofe, em hebraico, termo que 
de memória e trauma. "Se eu me esquecer de ti, Jerusalém” impõe a necessidade de se pensar Jerusalém como testemunho; resistência ao esquecimento e ao apagamento imposto.

Hannah Arendt em Eichmann em Jerusalém escreve que "é verdade que a dominação totalitária tentou estabelecer esses buracos de esquecimento nos quais todos os feitos bons e maus desapareceriam [...]" (ARENDT, 1999, p. 254). Tudo no hospital Georg Rosenberg colabora para isso, afinal, Georg Rosenberg "era uma casa feita para eliminar mistérios, como dizia o médico-gestor Gomperz" (TAVARES, 2006, p. 92). Às vezes, o doutor interrogava os pacientes com a pergunta: "Sabes em que é que deves pensar?” (TAVARES, 2006, p. 94). Queria ele que todos os pacientes se esquecessem de tudo o que viveram antes de Georg Rosenberg e, paradoxalmente, que também se esquecessem da violência sofrida naquele lugar. De tal modo, que:

Havia, pois, como que um arredondamento da existência, o que era excessivo transformava-se em alvo médico: tentava eliminar-se essa coisa, pôr de fora, coloca-la para além desse arredondamento. Como se cada existência, exactamente como um compartimento, tivesse um caixote do lixo, um sítio específico, com formas adequadas, para onde se deveriam atirar os hábitos, acções e, se possível, os pensamentos que não interessavam. Neste caso que não interessavam a quem vigiava: os médicos. O que era atirado para o caixote de lixo de cada indivíduo não era, pois, selecionado pelo próprio, mas sim pela terapêutica. E a dificuldade desta não estava no acto de atirar para o lixo, de uma única vez, algo que, pertencendo à personalidade de alguém, o prejudicava, o difícil era que a caixa de resíduos perigosos - assim eram considerados - de uma determinada existência fosse esquecida. (TAVARES, 2006, p. 92-3).

Por isso, "Se eu me esquecer de ti, Jerusalém" soma-se com "lembra-te que já estiveste cá fora; ou melhor: não te esqueças" (TAVARES, 2006, p. 160). Por sua vez, "Se eu me esquecer de ti, Georg Rosenberg", indica a necessidade de a personagem lembrar-se do $50)$. 
trauma sofrido. Não se esquecer de Georg Rosenberg é não se esquecer do trauma e enfrentar os vazios criados pelas palavras e atitudes do médico autoritário Gomperz.

A abordagem adotada por Gomperz consistia em apagar todos os hábitos de seus pacientes e cultivar, de certo modo, um tipo de vazio ou o "arredondamento da existência" (TAVARES, 2006, p. 92). O vazio, nesse sentido aqui é entendido como a "sensação que provém, em geral, da incapacidade para fazer algo de eficaz a respeito da própria vida e do mundo em que vivemos” (MAY, 1986, p. 17). Há um esforço empreendido pelo doutor e pelo hospital em geral para nivelar a existência e a experiência de seus pacientes a partir de um processo de apagamento e esvaziamento do sujeito, pois, "o homem indiferente não se apega a nada, não tem certeza absoluta, adapta-se a tudo, as opiniões são suscetíveis de modificações rápidas” (LIPOVETSKY, 2005, p. 26). Os pacientes tornam-se dóceis, administráveis, influenciáveis de forma que sua existência perde o sentido. Em "Se eu me esquecer de ti, Georg Rosenberg", há reminiscência e intimação do fragmento bíblico, produzindo novos sentidos. O fragmento em tela não se limita ao contexto bíblico, ao contrário, marca o deslizamento de sentido de Georg Rosenberg, que personifica a dominação totalitária, o "arredondamento da existência", a violência, a barbárie e o trauma sofrido por Mylia e suscita a memória de Alfred Rosenberg, o ideólogo racial e líder do escritório de promoção à cultura, educação e literatura do Reich ${ }^{5}$.

Jerusalém é um nome polissêmico e suas implicações são inúmeras. Em uma entrevista concedida em Portugal, Gonçalo M. Tavares também problematiza essa questão, afirmando que:

Não me interessa muito situar no holocausto ou não holocausto, ou seja, uma experiência que eu tive, tenho tido, felizmente, com os leitores de diferentes países é a identificação. Por exemplo, pessoas da Europa, do meio da Europa identificam-se, pessoas da ex-Iugoslávia identificam esse livro com o seu mundo, pessoas da Argentina

\footnotetext{
5, Alfred Rosenberg foi chefe do Escritório do Reich para a promoção da literatura alemã (Reichsstelle zur Förderung des Deutschen Schrifttums) e Comissário do Führer para a supervisão de toda a educação intelectual e filosófica do Reich (Beauftragter der Fübrers für die Überwachung der gesamten geistigen und weltanschaulichen Schulung und Eræiebung der NSDAP. DBFU). (SCHOEPS, 2004, p. 40).
} 
ou pessoas da América do Sul identificam alguma ideia da violência imanente dos livros com a sua experiência. Portanto, vários leitores remetem com o seu mundo esses acontecimentos. E, infelizmente, lamenta, digamos, o que está nestes livros é uma reflexão sobre o medo, sobre a violência, sobre a agressividade, como é que isso gera, não é especifico de nenhum período histórico nem de nenhum espaço concreto geográfico (TAVARES, 2013).

$\mathrm{O}$ que atesta que a leitura desse fragmento - "Se eu me esquecer de ti, Jerusalém, que seque a minha mão direita" (TAVARES, 2006, p. 154) - no texto literário, em última análise, põe em diálogo vários discursos, várias vozes (e silêncios), bem como consciências. A identificação realiza-se na medida em que o leitor consegue estabelecer essas relações com outros textos, trazendo Jerusalém para a sua realidade. O romance é dinâmico e o leitor, segundo a concepção do próprio autor, como se pode perceber na citação, cumpre um papel fundamental, pois ele assume uma postura ativa e reflexiva buscando relações de sentido com outras obras.

Certamente que Jerusalém não se limita à representação da Shoah enquanto evento traumático, tal como argumenta o próprio autor. Jerusalém põe em perspectiva o trauma e as referências a Shoah estão a serviço da representação da experiência traumática como um todo. Para apreendê-la em toda sua dimensão, o romance recorre a esses vazios de memória que possibilitam deslizamentos de sentido. No capítulo XVI, Theodor Busbeck está diante dos documentos que reuniu para compor o seu tratado sobre o horror e a barbárie. Entre fotografias, estudos, testemunhos, ele lê as palavras de David Rousset ${ }^{6}$ (sobrevivente dos campos de concentração nazistas): "os homens normais não sabem que tudo é possível" (TAVARES, 2006, p. 126)7 . A rigor, toda experiência inenarrável encontra o seu meio, mas

\footnotetext{
${ }^{6}$ David Rousset foi um militante francês, nascido na França em 1912. Estudou filosofia e literatura em Sorbonne Paris. Em 1936, fundou a Juventude Socialista Revolucionária e o Partido Operário Internacionalista. Devido a sua ação junto à resistência francesa, foi capturado em 1944 e levado ao campo de Buchwald e depois para Neuengamme. Foi libertado em abril de 1945. (fonte: https://www.buchenwald.de/en/1248/

${ }^{7}$ As palavras de David Rousset também aparecem em As origens do totalitarismo, de Hannah Arendt, sob a forma de epígrafe da terceira parte, intitulada Totalitarismo.
} 
tal citação põe em cheque a narrabilidade da experiência traumática pela palavra. "Aquele que testemunha sobreviveu - de modo incompreensível - à morte [...] Se o indizível está na base da língua, o sobrevivente é aquele que reencena a criação da língua” (SELIGMANN-SILVA, 2012, p. 52). Ao que parece a palavra falada ou a palavra escrita são, de toda forma, insatisfatórias, para a representação da imagem traumática. A palavra, antes, mostra-se como impossibilidade que como alternativa de expressão. Por isso, Jerusalém, ao tratar do trauma, põe em perspectiva o silêncio decorrente do vazio.

De modo que ao abordar o trauma, a narrativa se organiza em torno do seu próprio vazio. O romance abstém-se de reescrever o trauma, como se jamais pudesse traduzir o indizível por palavras. Jerusalém então recorre, mais uma vez, à citação (aderindo ao que postula Gérard Genette). Ao citar um fragmento de $A$ imagem do inferno, de Hannah Arendt, o narrador admite a impossibilidade de traduzir em palavras a experiência traumática, optando, portanto, pela citação de um fragmento que tampouco surgiu em texto de Hannah Arendt, mas que reverbera múltiplos discursos, vozes e consciências de testemunhas da Shoab:

Theodor Busbeck pegou num dos livros que tinha à sua frente e leu: "[...] seis milhões de seres humanos foram arrastados para a morte sem terem a possibilidade de se defender e, mais ainda, na maior parte dos casos, sem suspeitarem do que lhe estava a acontecer. O método utilizado foi a intensificação do terror. Houve, de começo, a negligência calculada, as privações e a humilhação [...]. Veio a seguir a fome, à qual se acrescentava o trabalho forçado: as pessoas morriam aos milhares, mas a um ritmo diferente, segundo a resistência de cada um. Depois, foi a vez das fábricas de morte e todos passaram a morrer juntos: jovens e velhos, fracos e fortes, doentes ou saudáveis; morriam não na qualidade de indivíduos, quer dizer, de homens e de mulheres, de crianças ou de adultos, de rapazes ou de raparigas, bons ou maus, bonitos ou feios, mas reduzidos ao mínimo denominador comum da vida orgânica, mergulhados no abismo mais sombrio e mais profundo da igualdade primeira: morriam como gado, como coisas que não tivessem corpo nem alma, ou sequer um rosto que a morte marcasse com o seu selo.”

"É nesta igualdade monstruosa, sem fraternidade nem humanidade - uma igualdade que poderia ter sido partilhada pelos cães e pelos gatos - que se vê, como se nela se reflectisse, a imagem do Inferno.” 


\begin{abstract}
"Depois da entrada nas fábricas da morte, tudo se tornava acidental e escapava por completo ao controlo tanto dos que infligiam o sofrimento como dos que o suportavam. E foram muitos os casos em que aqueles que um dia infligiam o sofrimento se transformavam em vítimas no dia seguinte."

Theodor suspirou fundo e preparava-se para prosseguir a leitura quando ouviu alguém chamá-lo, em voz baixa. Um homem dirigiuse para si dobrando-se para falar:

- Doutor Theodor Busbeck?

- Sim?

- É o seu pai. Está a morrer. (TAVARES, 2006, p. 128-9, grifo nosso).
\end{abstract}

As partes destacadas nesta citação pertencem ao ensaio de Hannah Arendt, $A$ imagem do inferno ${ }^{8}$. Nesse ensaio, a autora escreve que a barbárie perpetrada pelos nazistas nos campos de concentração está "além da capacidade de compreensão humana” (ARENDT, 2008, p. 227). O que corrobora a ideia do inefável e do inapreensível, fazendo com que o episódio em questão seja "difícil de ser narrado" (ARENDT, 2008, p. 227). A autora ainda argumenta que a máquina nazista para poder justificar os seus atos diante do público teve que recorrer à técnica e à ciência (ou pseudociência). Ao pedir argumentos "científicos", eles criam uma atmosfera de indiferença pura. Como houvesse "indiferença por saturação, informação e isolamento" (LIPOVETSKY, 2005, p. 26). Theodor é um exemplo dessa indiferença por saturação. Ele se apropria dessa mesma lógica pseudocientífica para poder esboçar o seu gráfico do terror. 'Era dessa atmosfera geral de 'cientificidade', ao lado de uma tecnologia moderna e eficiente, que os nazistas precisam para suas fábricas de morte" (ARENDT, 2008, p. 233). Assim como ele precisava desse ar de 'cientificidade' para esboçar o seu gráfico.

Queria que meu estudo resultasse um gráfico - um único gráfico que resumisse, que permitisse estabelecer uma relação entre o horror e o tempo. Perceber se o horror está a diminuir ao longo dos séculos ou a aumentar. Se é estável. Repara que se descobrir que o horror 
tem uma certa estabilidade histórica, que mantém certos valores, digamos, de cinco em cinco séculos, se conseguir encontrar uma regularidade, estarei perante uma descoberta fundamental. (TAVARES, 2006, p.45).

E como os intelectuais nazistas mencionados por Hannah Arendt, Theodor Busbeck também cai em desgraça. A atitude disparatada do doutor era no sentido de tentar "dominar a história" (TAVARES, 2006, p.46). E a esse respeito Hannah Arendt avança, dizendo que "um dos aspectos mais medonhos do terror contemporâneo é que, sejam quais forem os seus verdadeiro motivos ou objetivos, ele aparece invariavelmente sob os traços de uma conclusão lógica e inevitável, extraída de alguma teoria ou ideologia” (ARENDT, 2008, p. 232). E, de fato, o Theodor queria ser o criador de uma teoria infalível sobre a barbárie. Mas, a sua tentativa é frustrada e ridicularizada:

Como era previsível, o estudo de Theodor Busbeck foi recebido particular hostilidade por cientistas que pertenciam a determinados povos, especificamente enunciados naquela terrível tabela final [...] Theodor profetizava como 'emissores do terror' como de indivíduos dos povos considerados por ele como futuros 'receptores do terror'. (TAVARES, 2006, p. 194).

Um dos comentadores da obra de Theodor Busbeck afirma que o seu estudo era fruto do trabalho de um louco e, aliás, uma das personagens recomenda: “[...] a internarse, dizia, por exemplo, no reputado hospício Georg Rosenberg, bem conhecido, aliás, de uns familiares seus" (TAVARES, 2006, p.195). É perceptível que a trajetória de Theodor acompanha os desdobramentos do ensaio de Hannah Arendt, inclusive quando essa personagem encara o desprezo de seus pares. Ressalta-se, apesar de tudo, que os colegas de Theodor, ao recomendarem Georg Rosenberg, deixam também transparecer sua fé na ciência e na técnica.

A técnica é colocada como uma solução para superação do fracasso humano. Entretanto, Mylia e Ernst não precisam de uma vida mediada pela ciência, pela técnica, pela medicina ou pela máquina, que parecem transformar o sujeito em objeto. Muito pelo contrário, essas personagens procuram por todos os meios vencer o vazio causados tanto pela 
experiência traumática quanto pela indiferença. Ernst, ao encontrar Mylia, "descobriu-a porque veio por um caminho imaterial. 'A alma do homem frequentemente o avisa melhor do que sete sentinelas colocadas em lugar alto"' (TAVARES, 2006, p. 153). A citação feita, dessa vez feita pelo narrador, é uma citação direta de um versículo bíblico extraído do Livro do Eclesiástico ${ }^{9}$. Essa citação é bastante importante para a caracterização da relação entre as personagens Ernst e Mylia e do trauma que ambas viveram.

O capítulo 37 do Livro do Eclesiástico inclui, entre outras coisas, conselhos e começa tratando da amizade e de verdadeiros amigos. Encontra-se, nesse capítulo, uma passagem que diz: "Não te esqueças de teu amigo nos teus pensamentos; no meio da riqueza, não percas a sua lembrança" (BÍBLIA, Eclesiástico, 37, 6). Em seguida, há passagens que traduzem a ideia de superação do vazio, do isolamento e do abandono, "quando conheceres um [...] cuja alma se irmana à tua [...] compartilhará da tua dor”' (BÍBLIA, Eclesiástico, 37, 15), tal como ocorre com Ernst e Mylia em determinado momento do romance, se realiza uma ligação que o narrador denomina "imaterial".

A dor vivida por essas personagens não encontra correspondência em nenhuma outra personagem desse romance. Lê-se que Mylia se apaixonara por Ernst Spengler "devido ao rosto" (TAVARES, 2006, p. 210). Mas em seguida, o narrador explica que "uma mulher lê outras letras no rosto, um outro entendimento" (TAVARES, 2006, p. 210). De fato, a relação entre Mylia e Ernst não é superficial, há como “uma matéria dupla, uma segunda pele, uma pele emocional” (TAVARES, 2006, p. 210). Ambos compartilham, com diferentes intensidades, a mesma emoção e a mesma dor. A dor, para o narrador de Jerusalém, é um “acontecimento interior” (TAVARES, 2013, p. 352), logo, uma sensação não visível e de certa forma não partilhável, ainda que "a linguagem por meio do alfabeto, mais uma vez, torna igual o diferente, simplifica, acalma-nos" (TAVARES, 2013, p. 347). A dor vivida pelas duas personagens não pode ser mediada pela técnica e jamais é colocada em

${ }^{9}$ Em Eclesiástico lê-se: "A alma de um santo homem descobre às vezes melhor a verdade que sete sentinelas postas em observação numa colina” (BÍBLIA, Eclesiástico, 37, 18). 
palavras. Ela não se simplifica em nível do alfabeto ou de uma teoria, ela permanece invisível, não partilhável, em suma, irredutível.

Mylia sofria de uma dor não localizável. "Concentrada a dor nesse sítio largo que não era um ponto [...]" (TAVARES, 2006, p. 8), ou seja, a possibilidade de determinar a sua origem ou o seu ponto de partida era nula. Mas, para Mylia "dor era uma palavra essencial” (TAVARES, 2006, p. 7) que "não a deixava concentrar-se num diálogo” (TAVARES, 2006, p. 9). A sua dor, portanto, não era verbalizada, mas defini-la dessa maneira "dor" era uma forma de explicar o que sentia. Como se pode perceber, do vazio nasce a dor que, por sua vez, precisa dos silêncios como via de expressão. Segundo Gonçalo M. Tavares:

[...] o mais relevante, nesse raciocínio [...] é a questão de que é, de facto, na linguagem que os conceitos se localizam e, portanto, se alterarmos a linguagem, se alterarmos as normais associações de palavras, estamos a construir novos conceitos, formas de explicar e interpretar acontecimentos. (TAVARES, 2013, p. 356).

E, de fato, a dor não verbalizável de Mylia e sua ligação imaterial com Ernst possibilita romper com a ordem verbal e expressar essa dor e o trauma por outra forma que não a palavra. Há algo de incomunicável e de indizível na dor de Mylia e, muito embora, sua dor fosse tampouco partilhável, Ernst, ao contrário de Theodor e Gomperz, não era indiferente àquela dor. Assim, em "a alma do homem frequentemente o avisa melhor do que sete sentinelas colocadas em lugar alto" (TAVARES, 2006, p. 153), as sete sentinelas da passagem bíblica simbolizam a indiferença do doutor Gomperz e dos "tratamentos" de Georg Rosenberg, bem como o olhar clínico do doutor Theodor Busbeck que diagnosticara Mylia. Cercada por médicos, enfermeiros e outros profissionais da saúde Mylia sofria, entre outras coisas, com a indiferença. "Os médicos, vários, à frente dela haviam-na utilizado: isto não tem solução. Só um milagre” (TAVARES, 2006, p. 17). Mais adiante:

O primeiro choque: apresentava um problema aos médicos: uma dor, estava doente; eis um problema, uma charada orgânica. E os médicos respondiam-lhe encolhendo os ombros, com certa tristeza 
mais ou menos profissional, mas sem acções, sem propostas: isto é irresolúvel. A sua doença não se pode tratar. Apresentara um problema aos médicos e estes devolviam-no, no mesmo estado, sem interferir: a questão intacta. Por que tenho de morrer. (TAVARES, 2006, p. 17-8).

A indiferença é a condição que aproxima Ernst de Mylia porque ele também é vítima da indiferença. No início do romance, por exemplo, Ernst Spengler está sozinho em um sótão "preparado para se atirar" (TAVARES, 2006, p. 7). David Le Breton, ao tratar sobre a indiferença, afirma que há "figuras inúteis, cujo desaparecimento um dia não é mais do que o ponto final de um processo já há muito começado” (LE BRETON, 1999, p. 101). A sua ideação suicida era "uma expectativa crescente, um convite a acção" (TAVARES, 2006, p. 214), que começara antes de Georg Rosenberg, mas que havia piorado com a abordagem do doutor Gomperz. Ernst infere ainda, sobre a indiferença, que: "Não o haviam ajudado (ele nada recebera), nem sequer o recuperaram (nada lhe haviam devolvido; não recebera algo que antes tinha)" (TAVARES, 2006, p. 188). Depois de ter tido alta do hospital Georg Rosenberg, Ernst convivia com o vazio diariamente. E “já há evidência de que se as pessoas não preencherem o vazio com atividades significativas encontrarão a apatia endêmica que gera a impotência, o vício e a hostilidade autodestruidora" (MAY, 1973, p. 119). Com efeito, a impossibilidade de lidar com o próprio vazio resulta, primeiramente, em uma tentativa de suicídio, depois em assassinato. "Ernst está com a pistola na mão, a tremer: a bala saiu" (TAVARES, 2006, p. 226). Ernst matara Hinnerk (um veterano de guerra) em um beco. Sua hostilidade autodestruidora tem origem no trauma, ou melhor, na experiência com os vazios provocados pelos traumas, especialmente aquele de ter sido afastado do filho que ele nem chegou a conhecer.

\section{Considerações Finais}

À luz dessas reflexões, Jerusalém, de Gonçalo M. Tavares, está comprometido com a representação do trauma. Os esforços empreendidos pelo autor combinam o resgate da potência necessária para traduzir o obscurantismo de um mundo intraduzível, repleto de vazios e de lacunas criadas pela experiência traumática. Márcio Seligmann-Silva lembra que 
a experiência traumática "não pode ser totalmente assimilada enquanto ocorre" (SELIGMANN-SILVA, 2003, p.48). Ele ainda afirma que "a linguagem é antes de mais nada o traço - substituto nunca perfeito e satisfatório - de uma falta, de uma ausência" (SELIGMANN-SILVA, 2003, p.48). Narrar o trauma é, portanto, contornar esses vazios, essas ausências, preenchê-las com sentido e, dessa forma, perceber o que as desencadeou.

O trauma, nesse sentido, é fragmentário e se dispersa no silêncio. Narrar aquilo que não pode ser narrado e que não se deixa narrar por formas narrativas puras, leva Jerusalém a recorrer a um imenso volume de fragmentos. A intertextualidade manifesta-se devido à dispersão do trauma e se realiza no ato da leitura dos silêncios. Daí decorre que Jerusalém é pleno de citações, de alusões, de reminiscências que, em seu conjunto, procuram recompor e reconstruir a experiência traumática das personagens. Sem recorrer aos intertextos, muito provavelmente, o narrador e as personagens não conseguiriam lidar com esses vazios deixados pelo trauma.

Diante dos vazios encontrados em Jerusalém, o leitor assume uma postura ativa e reflexiva buscando relações de sentido. Na tentativa de preencher esses vazios encontrados, os silêncios levam o leitor a encontrar o sentido "ausente". O leitor de Jerusalém ao ler o tetxo entrega-se ao silêncio. É que ler é impor silêncio a si mesmo, é traduzir o silêncio de cada palavra e simultaneamente alimentá-las com ele. No processo de leitura, os sentidos se atualizam e se complementam no silêncio, contornando, assim, os vazios deixados no romance. E em decorrência disso, o romance adquire a possibilidade de significar de muitas outras maneiras. Em razão disso, os intertextos presentes em Jerusalém suscitam sentidos que não cabem nestas páginas, tampouco se deixam aprisionar pelas palavras.

\title{
SILENCES AND EMPITNESS IN JERUSALEM: INTERTEXTUAL RELATIONS
}

\begin{abstract}
Jerusalem by Gonçalo M. Tavares, the basic object of analyzes undertaken in this article, establishes interlocutions with multiple discourses produced at different times. Among them are the philosophical, sociological and religious discourses. Intertextual relations occur both in the verbal domain and in the domains of silence. They present themselves explicitly, sometimes, and more veiled, by others. The main objective of this article is to articulate the interfaces between literature,
\end{abstract}


trauma, silence and emptiness in the light of intertextuality studies, especially by Julia Kristeva. Through silence and emptiness, memories of pain, suffer and death emerge. The emptiness that surrounds the characters of Jerusalem is filled with silences. Such enhanced silences reveal the existence of different discourses. Studies related to silence, developed by Eni P. Orlandi, are invited to support the discussions. With regard to the emptiness, it is mainly used to the notes of Gilles Lipovetsky.

PALAVRAS-CHAVE: Gonçalo M. Tavares; Intertextuality; Jerusalem; Silence; Emptiness.

\section{REFERÊNCIAS}

ARAÚJO, Júlio César; LOBO-SOUSA, Ana Cristina. Considerações sobre a intertextualidade no hipertexto. Linguagem em (Dis)curso (Impresso), v. 9, p. 565-583, 2009. Disponível em $<\quad$ http://www.scielo.br/scielo.php?script=sci_arttext\&pid=S1518-763220090003000 07>Último acesso: Mar/2018.

ARENDT, Hannah. A imagem do inferno. In: - Compreender: formação, exílio e totalitarismo. Tradução de Denise Bottman. São Paulo: Companhia das Letras; Belo Horizonte: Editora UFMG, 2008.

Eichmann em Jerusalém: um relato sobre a banalidade do mal. Tradução de José Rubens Siqueira. São Paulo: Companhia das Letras, 1999.

Letras, 1989.

Origens do totalitarismo. Tradução de Roberto Raposo. São Paulo: Companhia das

ASSMANN, Aleida. Espaços da recordação: formas e transformações da memória cultural. Campinas: Editora da Unicamp, 2011.

BARTHES, Roland. Rumor da língua. Tradução de Mário Laranjeira. São Paulo: Martins Frontes, 2004.

BÍBLIA, Bíblia Sagrada. Tradução de João José Pedreira de Castro. São Paulo: Editora Ave Maria, 1997.

FLORY, Alexandre Villibor. Linguagem e construção da realidade organizacional: uma análise bakhtiniana do discurso. São Paulo: Arte e Ciência, 2006.

KRISTEVA, Julia. Introdução à semanálise. Tradução de Lúcia Helena França Ferraz. São Paulo: Perspectiva, 2005.

LE BRETON, David. Do silêncio. Tradução de Luís M. Couceiro Feio Lisboa: Instituto Piaget, 1999.

LIPOVETSKY. Gilles. A era do važio: ensaios sobre o individualismo contemporâneo. Tradução de Therezinha Monteiro Deutsch. Barueri: Manolo, 2005. 
MAY, Rollo. Psicologia existencial. Tradução de Ernani Pereira Xavier. Rio de Janeiro: Globo, 1986.

ORLANDI, Eni Puccinelli. As formas do silêncio: no movimento dos sentidos. 6. ed. Campinas, SP: Editora da Unicamp, 2007. . Análise do discurso: princípios e procedimentos. Campinas: Pontes, 2009.

SAMOYAULT, Tiphaine. A intertextualidade: memória da literatura. Tradução de Sandra Nitrini. São Paulo: Aderaldo \& Rothschild, 2008.

SCIACCA, Michele Federico. Silêncio e Palavra. Tradução de Flávio Loureiro Chaves e Maria Teresa Pasquini. Porto Alegre: UFRGS, 1967.

SELIGMANN-SILVA. Marcio (org) História, Memória, Literatura. Campinas: Editora Unicamp, 2003.

SCHOEPS, Karl-Heinz. Literature and Film in the Third Reich. Tradução de Kathleen M. Dell'Orto. Rochester: Candem House, 2004. Disponível em: < https://books.google. com.br/books?id=p1yGRf6fmK0C\&printsec $=$ frontcover\&dq=Literature + and + Film + in + the + Third + Reich\&hl=pt-R\&sa=X\&ved=0ahUKEwjk5JeZzOnaAhVjtlkKHY-yBqEQ 6AEIKDAA\# $\#_{\mathrm{V}}=$ onepage\&q=Literature $\% 20$ and $\% 20$ Film $\% 20$ in $\% 20$ the $\% 20$ Third $\% 20$ Reich $\& f=$ false $>$ Acesso em: 06. Abr. 2018.

TAVARES, Gonçalo M. Atlas do corpo e da imaginação. Alfragide: Editorial Caminho: 2013. . Jerusalém. São Paulo: Companhia das Letras, 2006.

- Entrevista. In: Imagem da Palavra. [12 de Julho de 2013]. Disponível em: <https://www.youtube.com/watch?v=UA13VVdk2K4>. Acesso em: 06. Abr. 2018.

Recebido em: 03/05/2018. Aprovado em: 104/06/2018. 